\title{
The Effect of Microbiota on Colon Carcinogenesis
}

\author{
Kichul Yoon ${ }^{1,2}$, Nayoung Kim ${ }^{1,3}$ \\ 'Department of Internal Medicine, Seoul National University Bundang Hospital, Seongnam, ${ }^{2}$ Department of Internal Medicine and Digestive Disease \\ Research Institute, Wonkwang University Sanbon Hospital, Gunpo, ${ }^{3}$ Department of Internal Medicine and Liver Research Institute, Seoul National \\ University College of Medicine, Seoul, Korea
}

Although genetic background is known to contribute to colon carcinogenesis, the exact etiology of the disease remains elusive. The organ's extensive interaction with microbes necessitated research on the role of microbiota on development of colon cancer. In this review, we summarized the defense mechanism of colon from foreign organism, and germ-free animal models that have been employed to elucidate microbial effect. We also comprehensively discussed the metabolic property of microbiota such as butyrate production, facilitation of heme toxicity, bile acid transformation, and nitrate reduction that has been shown to contribute to the development of the tumor. Finally, up-to-date subjects such as the effect of age and gender on microbiota are briefly discussed.

(J Cancer Prev 2018;23:117-125)

Key Words: Microbiota, Colon, Carcinogenesis, Butyric acid, Bile acids and salts

\section{INTRODUCTION}

According to the International Agency for Research on Cancer estimates, in 2012, colorectal cancer accounted for $9.7 \%$ of all incident cancers in the world with 1.4 million cases and 694,000 deaths. That makes it the third most common cancer in men and the second in women. ${ }^{1.2}$ The human gastrointestinal tract represents one of the largest interfaces $\left(250-400 \mathrm{~m}^{2}\right)$ between the host, environmental factors and antigens in the human body. ${ }^{3}$ The dense communities of bacteria in the lower intestine $(\geq$ $10^{12} / \mathrm{cm}^{3}$ ) are separated from body tissues by the epithelial layer $(10 \mu \mathrm{m})$ over the surface area. ${ }^{4}$ Human intestinal microbiota is composed of $10^{13}$ to $10^{14}$ microorganisms with microbiome (collective genome) of at least 100 times as many genes as our own genome. ${ }^{5}$ According to revised estimates, the number of bacteria in the body is about the same order as the number of human cells, and their total mass is about $0.2 \mathrm{~kg}$. ${ }^{6}$ This microbiome encompasses all genes for processes, such as substrate breakdown, protein synthesis, biomass production, production of signaling molecules, and antimicrobial compounds. ${ }^{7}$ It also encodes biochemical pathways that humans have not evolved. ${ }^{7}$ The intestinal microbiota can therefore be regarded as a separate organ within the human host, that is capable of even more conversions than the human liver. ${ }^{8}$ There is mounting evidence that dysbiosis, a state of pathological imbalance in the gut microbiome is present in many disease states, including colorectal neoplasm. ${ }^{9}$ In addition, there are many articles that published the effect of sex hormone, aging and fungi on the colon cancer. However, there have been few comprehensive review articles regarding the effect of microbiota on the colorectal neoplasm. From this background we tried to summarize the metabolic factors such as bile acid and butyrate which affect colon carcinogenesis in terms of the microbiota.

Received September 14, 2018, Revised September 20, 2018, Accepted September 21, 2018

Correspondence to: Nayoung Kim

Department of Internal Medicine, Seoul National University Bundang Hospital, 82 Gumi-ro 173beon-gil, Bundang-gu, Seongnam 13620, Korea Tel: +82-31-787-7008, Fax: +82-31-787-4051, E-mail: nayoungkim49@empas.com, ORCID: Nayoung Kim, https://orcid.org/0000-0002-9397-0406

Copyright (C) 2018 Korean Society of Cancer Prevention

(c) This is an Open Access article distributed under the terms of the Creative Commons Attribution Non-Commercial License (http://creativecommons.org/licenses/by-nc/4.0) which permits unrestricted non-commercial use, distribution, and reproduction in any medium, provided the original work is properly cited. 


\section{COLORECTAL NEOPLASM}

The widely accepted classic model for colorectal tumorigenesis suggests that at least 5 to 7 major molecular alterations are needed to occur for a normal epithelial cell to proceed to carcinoma. ${ }^{10}$ The colorectal tissue environment is unique in that the intestinal mucosal surface is continuously exposed to a vast community of microorganisms. ${ }^{11}$ Bacteria have been linked to colorectal cancer by production of toxic and genotoxic bacterial metabolites which can bind specific cell surface receptors and affect intracellular signal transduction. ${ }^{12}$ A large body of evidence supports a relationship between infective agents and human cancers and suggests that certain mucosa-associated bacterial species play an important role in the pathogenesis of colorectal cancer ${ }^{12,13}$ A recent human study further reported the complex mechanism of colonic carcinogenesis regarding microbiota with the difference in colitis associated cancer and sporadic cancer. ${ }^{14}$ General mechanisms for microbiota-related colon cancer is summarized in Figure 1. ${ }^{15}$

\section{DEFENSE MECHANISM OF COLON}

In a mouse model of colon, two distinct layers of mucus were found. The firm mucus layer of colon is dense and has a high mucin2 (Muc2) concentration. ${ }^{16}$ Probably according to the physical blockage of small sized pores, the inner layer doesn't carry bacteria. In contrast, the 'movable' outer layer which is colonized by bacteria has an expanded volume from the proteolytic cleavages of the Muc2. ${ }^{16}$ Mucosal compartmentalization functions to minimize exposure of resident bacteria to the systemic immune system. ${ }^{4}$ Typically, commensal microorganisms that penetrate the intestinal epithelial cell barrier are phagocytosed and eliminated by lamina propria macrophages. ${ }^{17}$

Human mucosal barrier mainly consists of conventional colonic epithelial cells. Epithelial cells are maintained on a network of interconnected myofibroblasts. Goblet cells are important for producing both mucus and trefoil peptides, and enteroendocrine cells produce paracrine molecules. ${ }^{18}$ The intraepithelial diffuse lymphocytes, intramucosal and submucosal follicles and patches form the barrier against organisms, such as bacteria, viruses, parasites and fungi. ${ }^{18,19}$

Innate immunity is the basic mechanism of mucosal defense. Pattern recognition receptors such as Toll-like receptors enables mammalian cells to recognize conserved characteristic molecules on microorganisms and they are known as pathogen-associated molecular patterns. ${ }^{18,20}$ Bacteria and their products affects the gut permeability to antigen. ${ }^{21}$ Epithelial cytokines are influenced by factors in the luminal microflora and they regulate the status of local $\mathrm{T}$ cells, B cells macrophages and polymorphs. ${ }^{21}$

While the immune system prevents microbial colonization, it paradoxically facilitates the establishment of gut microbiota. ${ }^{22}$ Specifically, immunoglobulin A (IgA) has been suggested to help bacterial adherence to intestinal epithelial cells. ${ }^{22}$ Donaldson et $\mathrm{al}^{22}$ recently reported the IgA-enhanced colonization on mucosa for the species of gut microbiome including the multiple strains of Bacteroides fragilis.

\section{GERM-FREE ANIMAL MODEL}

Germ-free animal models have been employed to investigate

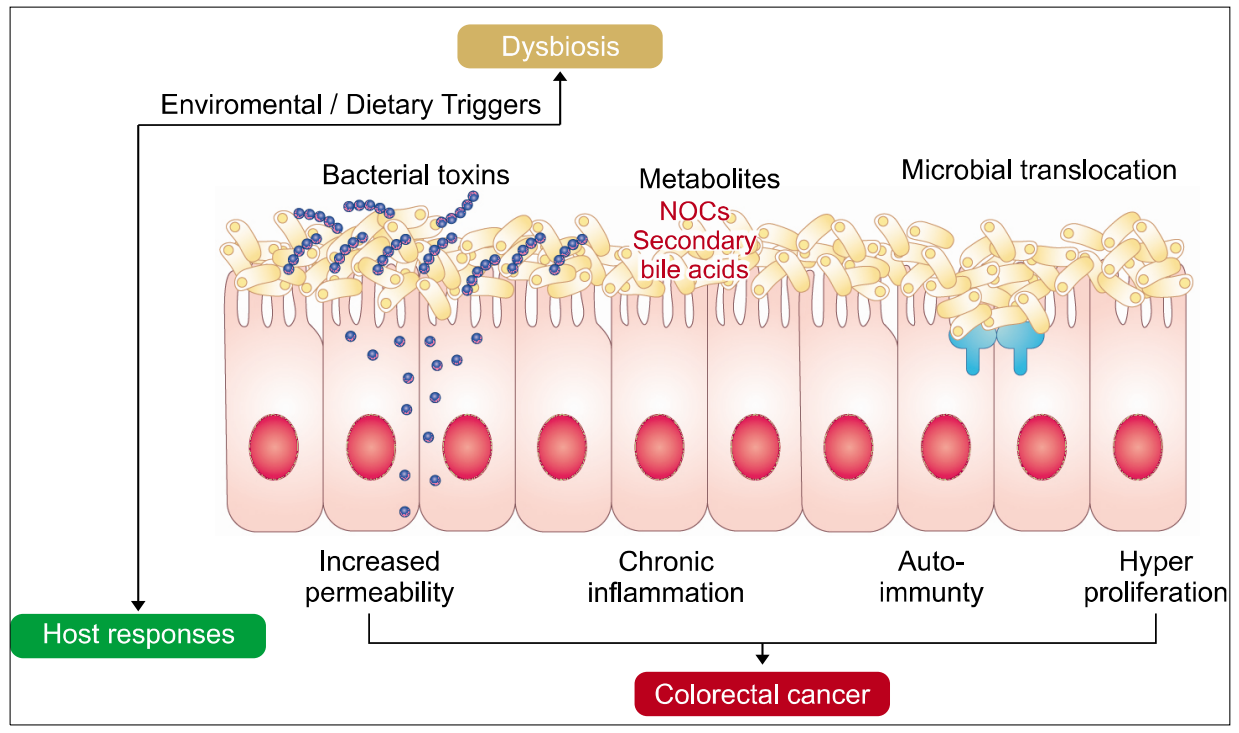

Figure 1. General mechanisms for microbiota-related colon cancer. Bacteria and their products affect the gut permeability to antigen. Dietary substrates undergo bacterial metabolism to form potentially carcinogenic products such as NOCs and secondary bile acids. Accordingly, chronic inflammation and genotoxicity contribute to the colon tumorigenesis. NOCs, $\mathrm{N}$-nitroso compounds. Adapted from Sun and Kato. ${ }^{15}$ 
the interaction between gut microbiota and host in carcinogenesis. Gut commensal microbes colonizing neonatal mammals increase specific and natural antibodies against the microbiota, thereby affecting the immune system development. ${ }^{23}$ When carcinogens such as 1,2-dimethylhydrazine (DMH) and azoxymethane (AOM) were administered, DMH induced colonic tumors in $20 \%$ of germ-free rats and in $93 \%$ of conventional rats. ${ }^{24}$ $\mathrm{AOM}$ increased the multiplicity of colonic tumors in germ-free and gnotobiotic rats contaminated with Clostridium perfringens, as compared to conventional Rats. ${ }^{24}$

Vannucci et al. ${ }^{19}$ performed subcutaneous injection of carcinogen AOM and promoter porcine bile to germ-free and conventional rats. They found that germ free rats showed a lower susceptibility to induction and development of colorectal cancers, and a more active anticancer immune response than conventional rats. ${ }^{19}$ Germ-free rats showed enhanced immunity represented by natural-killer cells and natural-killer T (NKT) lymphocytes, and increased number and augmented function of both cytotoxic $\mathrm{T}$ cell and B cells, while conventional rats had increased $\mathrm{T}, \mathrm{T}$ helper and NKT cells and a reduction in $\mathrm{B}$ lymphocytes. ${ }^{19}$ They hypothesized that immunological activation to commensal microflora may increase the spectrum of tolerance to antigens, thereby impeding the host's anticancer response. ${ }^{19}$

T-cell receptor $\beta$ chain and 553 double-knockout mice $\left(\mathrm{TCR}^{-1-}\right.$ $\mathrm{p}^{53^{-/-}}$) shows high incidence of spontaneous colorectal cancer. ${ }^{25}$ Kado et al. ${ }^{26}$ conducted a study to investigate the role of intestinal microflora for development of adenocarcinoma in the p53 double-knockout mouse model. In conventional mice, adenocarcinomas of ileocecum and cecum were detected in $70 \%$ of animals. In contrast, in grem-free mice, the development of adenocarcinoma was completely suppressed. ${ }^{26}$

On the other hand in familial adenomatous polyposis mouse model (C57BL/6-Apc ${ }^{\mathrm{Min} /+}$ ), there was no significant difference in development of adenoma in the intestine between germ-free mice and conventional animals. ${ }^{27}$ However, a recent report by Tomkovich et al. ${ }^{28}$ employing germ-free, specific-pathogen-free and gnotobiotic $\mathrm{ApC}^{\mathrm{Min} /+} ; \mathrm{Il10^{-/- }}$ mice model found that the colon tumorigenesis was related to inflammation. They showed that tumor was practically abolished in germ-free $\mathrm{Apc}^{\mathrm{Min} /+} ; 110^{-/-}$ and pks ${ }^{+}$Escherichia colipromoted tumorigenesis in the Apc ${ }^{\mathrm{Min} /+} ; 1110^{-/-}$ model in a colibactin-dependent manner. ${ }^{28}$

The role of microflora on the development of intestinal neoplasm varied according to the genetic background. According to aforementioned studies employing germ-free animals, there have been a trend that conventional microbiota is needed for carcinogenesis especially in sporadic colon cancer model.

\section{METABOLIC PROPERTY OF MICROBIOTA IN TUMORIGENESIS}

Metabolic property of gut bacterial population has been investigated in relation to tumorigenesis. Specific metabolic processes and products are discussed here (Fig. 2). ${ }^{29}$

\section{Butyrate}

Colon microbiota depends on the dietary residues that avoided the digestion and absorption. ${ }^{30}$ Typically, dietary fibers are fermented by microbiota of large intestine because they are not degraded and absorbed in the small intestine. ${ }^{31}$ Consumption of a balanced diet predominantly yields carbohydrate residues

\begin{tabular}{|c|c|c|c|}
\hline Dietary compounds & Microbial role & & Known effect on host \\
\hline $\begin{array}{l}\text { Non-digestible } \\
\text { carbohydrates }\end{array}$ & SCFAs production & $\longrightarrow$ & $\begin{array}{l}\text { Microbiota modulation; } \\
\text { Antiinflammation; } \\
\text { Tumor cell growth suppression } \\
\text { vs. Promotion of polyp (?) }\end{array}$ \\
\hline Protein & NOCs production & $\longrightarrow$ & $\begin{array}{l}\text { ROS production; } \\
\text { genotoxicity }\end{array}$ \\
\hline Heme & $\begin{array}{l}\text { Facilitating } \\
\text { Heme toxicity }\end{array}$ & $\longrightarrow$ & $\begin{array}{l}\text { Microbiota modulation; } \\
\text { cytotoxicity; genotoxicity }\end{array}$ \\
\hline Fat $\rightarrow$ bile acids & $\begin{array}{l}\text { Secondary bile } \\
\text { acid production }\end{array}$ & $\longrightarrow$ & $\begin{array}{l}\text { Microbiota modulation; } \\
\text { cytotoxicity; genotoxicity }\end{array}$ \\
\hline
\end{tabular}

Figure 2. Dietary compounds and the role of microbiota in colon carcinogenesis. Specific food compounds that are related to microbiota, and have a role in colon carcinogenesis, are shown. SCFAs, short-chain fatty acids; NOCs, N-nitroso compunds; ROS, reactive oxygen species. Adapted from Louis et al. ${ }^{29}$ with original copyright holder's permission. 
such as fiber, which stimulates saccharolytic fermentation and the production of short-chain fatty acids (SFCAs). Bacteria with an almost exclusive saccharolytic metabolism are generally considered to be beneficial because of their metabolic function and end products. Such a metabolic function is typical for lactobacilli and bifidobacteria. $^{31}$ Among SCFAs, butyrate has been investigated extensively.

\section{1) Role of butyrate}

The SCFAs, namely acetate, butyrate, and propionate are quantitatively and metabolically the most important microbial end-products of the human colon fermentation process. ${ }^{29,32}$ Among them, butyrate produced by fermentation of dietary fiber is considered to be the main reason for the health benefit from the indigestible carbohydrate. ${ }^{33}$ Butyrate is the preferred energy source for the colonic mucosa, and all three SCFAs have antiinflammatory and antiproliferative properties. ${ }^{30}$ Meanwhile, butyrate suppresses the growth of tumor cells. The most investigated mechanism is that butyrate inhibits histone deacetylases (HDAC) and thus results in inactivation of many oncogenic signaling pathways. ${ }^{34}$ The metabolic rearrangement in cancerous colonocytes is an appropriate means for providing biomaterials as well as energy that are essential for growth (Warburg effect). Therefore, butyrate accumulates and functions as an HDAC inhibitor. ${ }^{35}$ The effect of butyrate has been reported to differ according to dosage. Lower doses of butyrate have a differential effect on cell proliferation depending on the Warburg effect, while higher doses of butyrate was shown to inhibit proliferation regardless of the Warburg effect. ${ }^{35}$ Butyrate is metabolized to acetyl-CoA, the dose of butyrate determines the utilization of epigenetic mechanisms. ${ }^{35}$ A high dose of butyrate $(5$ $\mathrm{mM}$ ) is a potent HDAC inhibitor, while at low doses such as 0.5 $\mathrm{mM}$, butyrate might induce histone acetylation by an alternative mechanism that is distinct from its role as an HDAC inhibitor. ${ }^{35}$

Butyrate induces cell differentiation, promotes cell apoptosis and reduces tumor cell invasiveness. ${ }^{36}$ Human study revealed that high red meat consumption increased the levels of pro-oncogenic microRNA including miR-17-92 cluster in rectal biopsies, and increased butyrate supply through consumption of a butyrylated-resistant starch restored the miR-17-92 miRNAs to baseline levels. ${ }^{37}$ Butyrate insufficiency may contribute to the development of inflammatory conditions because the acid has been shown to induce the differentiation of colonic $\mathrm{T}$ regulatory lymphocytes, which suppress inflammatory and allergic responses. ${ }^{38,39}$ Gut microbial metabolite butyrate was shown to suppress development of colon carcinogenesis in $\mathrm{Apc}^{\mathrm{Min} /+}$ mice due to its Gpr109a agonist property through $\mathrm{T}$ regulatory cell differentiation. ${ }^{40}$

\section{2) Butyrate producing bacteria}

Bifidobacteria are Gram-positive, anaerobic, saccharolytic bacteria belong to the phylum Actinobacteria. ${ }^{32}$ Most butyrate producers in the human colon belong to the Firmicutes phylum and in particular Clostridium clusters IV and XIVa. ${ }^{32}$ Clostridial clusters IV and XIVa butyrate producers are Gram-positive, highly oxygen-sensitive, anaerobic and saccharolytic bacteria. The two dominant bacterial species are Faecalibacterium prausnitzii (up to $14 \%$ of the total fecal microbiota, clostridial cluster IV) and Eubacterium rectale (up to $13 \%$ of the total fecal microbiota, clostridial cluster XIVa). ${ }^{32,41}$ Adding a fermentable fiber (inulin) to the diet of obese women increased counts of $F$ prausnitzii and other clostridial bacteria and reduced systemic inflammation. ${ }^{42}$ Pyrosequencing study revealed the difference in fecal microbial poulation patterns between colorectal cancer and healthy subjects. ${ }^{43}$ Phylotypes closely related to Bacteroides were prevalent in the cancer patients, while the butyrate producing Faecalibacteriumand Roseburiawere significantly less abundant. ${ }^{43}$ The abundance of Bacteroides species and colorectal cancer status was positively correlated. ${ }^{43}$ Potentially pathogenic Fusobacterium and Campylobacter species were more abundant in colorectal cancer patients than in the controls. ${ }^{43}$ A cross-sectional study measured the fecal samples from African Americans with a high risk of colon cancer and rural native Africans with a low risk for the disease. ${ }^{30}$ Native Africans had significantly higher abundance in the butyrate-producing bacteria such as $F$ prausnitzii, Clostridium cluster IV, and Clostridium cluster XIVa, while Bacteroides was the dominant microbial composition of African Americans. $^{30}$

\section{3) Controversy on butyrate}

Although SFCAs including butyrate have been generally shown to be beneficial, several challenging reports also exist. Several key studies on the relationship between butyrate, microbiota and colon cancer are summarized on Table 1 . $^{37,38,40,44-50}$

Higher fecal SCFA concentration correlated positively with metabolic syndrome risk factors, such as adiposity, waist circumference and homeostatic model assessment index, and inversely with high-density lipoprotein. ${ }^{51}$ Significantly high concentrations of butyrate and propionate in obese children compared with normal-weight children were also reported. ${ }^{52}$

A classic animal study using DMH colon cancer model showed that sodium butyrate treatment enhanced the development of 
Table 1. Key studies on butyrate and microbiota regarding colon cancer

\begin{tabular}{|c|c|c|c|}
\hline Author (year) & Study subject & Protocol & Effect of butyrate on colon \\
\hline Whitehead et al. $(1986)^{44}$ & Cell line LIM1215 & In vitro & Differentiating effect \\
\hline Freeman $(1986)^{45}$ & Wistar rats & In vivo $\mathrm{DMH}$ & Enhancing the development of colonic neoplasia \\
\hline Deschner et al. $(1990)^{46}$ & CF1 Mice & In vivo $\mathrm{AOM}$ & No difference in dysplasia or tumor \\
\hline Archer et al. $(1998)^{47}$ & Cell line HT-29 & In vitro & Growth inhibition \\
\hline O'Keefe et al. $(2009)^{48}$ & Human & Cross-sectional & Higher fecal butyrate in Native Africans \\
\hline Donohoe et al. $(2011)^{49}$ & C57BL/6 mice & Ex vivo $\mathrm{CV}$ vs. GF & Stimulating colon epithelial cell proliferation \\
\hline Furusawa et al. $(2013)^{38}$ & Mice $^{\mathrm{a}}$ & In vitro, in vivo & Inducing differentiation of colon Tregs \\
\hline Belcheva et al. $(2014)^{50}$ & $\mathrm{APC}^{\mathrm{Min} /+} \mathrm{MSH}^{-1-}$ mice $^{\mathrm{b}}$ & In vivo & Inducing aberrant proliferation and transformation \\
\hline Singh et al. $(2014)^{40}$ & Niacr ${ }^{-1-}$ mice $^{c}$ & In vivo, ex vivo $\mathrm{AOM}+\mathrm{DSS}$ & Suppressing colon inflammation and carcinogenesis \\
\hline Humphreys et al. $(2014)^{37}$ & Human & Randomized trial & Restoring oncogenic miRNA to baseline \\
\hline
\end{tabular}

DMH, 1,2-dimethylhydrazine; AOM, azoxymethane; CV, conventional; GF, germ-free; Tregs, regulatory T cells; DSS, dextran sulfate sodium; miRNA, microRNA. a GF IQI, C57BL/6 mice, Myd $88^{-1-}$ Ticam $1^{-1-}$ mice, OT-II transgenic mice. ${ }^{b} \mathrm{C} 57 \mathrm{BL} / 6 \mathrm{~J}$ background. ${ }^{\mathrm{C}}$ 57BL/6 background.

colon neoplasm, while having increased fecal butyric acid concentration. ${ }^{45}$ To seperate the effect of sodium, tributyrin was administered to AOM mouse model. Although tributyrin feeding resulted in 10-fold increase in butyric acid in feces, AOM induced dysplasia or colon tumor showed no difference between the tributyrin fed and control mice. ${ }^{46}$ Recently, direct instillation of sodium butyrate to represent the concentration of the SCFA in the distal part of the colon resulted in aberrant proliferation and transformation of colon epithelial cells in $\mathrm{APC}^{\mathrm{Min} /+}$ MutS Homolog $2^{-1-}$ mice. $^{50}$

This discrepancy regarding the effect of butyrate on colon neoplasm could partly be attributed to the fiber itself that could play as a confounder. ${ }^{53}$ Many studies testing the effect of butyrate on colon cancer development used dietary fiber as their source for butyrate production. However, the fiber may have independent effects from that of butyrate. ${ }^{53}$ Dietary fiber can dilute possible carcinogens by increasing fecal bulk. ${ }^{54}$ It also shortens time for proteolytic fermentation which may result in tumorigenic metabolites. Fiber could also bind carcinogens such as secondary bile acids. ${ }^{54}$ Furthermore, many fibers contain health-promoting substances such as phytate and phytosterols. ${ }^{53}$ In addition, the difference between in vitro vs. in vivo vs. human study can be another important factor explaining the discrepancy in the results. ${ }^{53}$

Recently, a probiotic clinical trial proposed a 'rebalancing' of butyrate concentration by administrating Lactobacillus paracasei DG. ${ }^{55}$ Interestingly, they found that the effect of the probiotic on the microbiota and SFCAs was associated with initial fecal butyrate concentration..$^{55}$ Specifically, objects with inital butyrate higher than $100 \mathrm{mmol} / \mathrm{kg}$ of wet feces showed reduction in butyrate and decrease in Colostridales genera. In contrast, for those with initial butyrate lower than $25 \mathrm{mmol} / \mathrm{kg}$, the probiotic treatment increased butyrate concentration and decreased Ruminococcus. based on these results, they suggested that fecal butyrate concentration may represent a biomarker to classify the subjects who might benefit from the probiotic treatment. ${ }^{55}$

\section{2. $\beta$-glucuronidase}

Kim and $\mathrm{Jin}^{56}$ investigated the relationship between intestinal bacterial $\beta$-glucuronidase and colon cancer. After sonication of fecal specimens, the $\beta$-glucuronidase activity of colon cancer patients was 12.1 times higher than that of the controls. ${ }^{56}$ Animal study was also performed to elucidate the inducing factor for $\beta$-glucuronidase by injecting DMH and benzo[a]pyrene to rats. The bile from DMH- and benzo[a]pyrene-treated rats induced $\beta$-glucuronidase in $E$. coli $\mathrm{HGU}-3$, a $\beta$-glucuronidase producing bacterium from human intestine. ${ }^{56}$ The result implied the role of bacteria in converting the pro-carcinogens to carcinogen in the gut. $^{57.58}$

\section{Nitroso compunds}

N-nitroso compounds (NOC) are known to exert highly carcinogenic effects following the formation of potent DNA alkylating agents during metabolism. The apparent total $\mathrm{N}$-nitroso compound (ATNC) in food is generally non-detectable, the measurable fecal concentration of ATNC is suggested to be produced endogenously by N-nitrosation. ${ }^{59,60}$ Although most dietary nitrate and nitrite are absorbed in upper gastrointestinal tract and excreted in the urine, people consuming a large amount of red meat can have nitrosating agents through colon. ${ }^{61}$

Nitrate present in food and water is reduced by gut bacterial nitrate reductase to nitrite. Then nitrite reacts with nitrogenous compounds to produce NOC. ${ }^{12,60}$ Laboratory studies have shown that the bacterial strains belonging to Escherichia, Pseudomonas, 
Proteus, Klebsiella, and Neissera families nitrosate the nitrogenous precursors. $^{60,61}$ And the nitrate and nitrite reductase genes regulate the $\mathrm{N}$-nitrosation activity. ${ }^{60}$ Most of these microbiota belong to facultative anaerobes that can also use nitrate or nitrite for respiratory denitrification by reducing nitrate to nitrite, NO, $\mathrm{N}_{2} \mathrm{O}$ and $\mathrm{N}_{2} \cdot{ }^{61}$ ATNC investigated in germ-free and conventional microflora rats supports this concept, showing the ATNC in the stomach and large intestine of the conventional animals were formed by microbial action. ${ }^{62}$

\section{Heme}

Heme iron is more abundant in red meat than white meat and fish, and they mediate transportation of nitrosating agents. ${ }^{61}$ Dietary heme was also reported to alter the microflora by decreasing the number of Gram-positive bacteria, leading to expansion of Gram-negative community. ${ }^{63,64}$ An animal study reported that mice fed with a diet supplemented with heme showed a damaged gut epithelium and hyperproliferation. ${ }^{65}$ The damage and hyperproliferation was not observed in mice that received heme and antibiotics together, implying the role of microbiota in heme-induced epithelial hyperplasia. ${ }^{65}$ In the study, antibiotics were shown to block heme-induced differential expression of oncogenes, tumor suppressors, and cell turnover genes, implying that antibiotic treatment prevented the hemedependent cytotoxicity to the epithelium. The protective effect of antibiotics was attributed to elimination of sulfide-producing bacteria and mucin-degrading bacteria such as Akkermansia, because sulfide reduces disulfide bond to cause mucin denaturation. ${ }^{65}$

A recent study also reported that dietary heme induces gut dysbiosis such as a decrease in $\alpha$-diversity, a reduction of Firmicutes and an increase of Proteobacteria, particularly Enterobacteriaceae. ${ }^{66}$ The change was similar to dextran sodium sulfate-induced colitis model. A reduction in fecal butyrate levels was also found in mice fed the heme supplemented diet, compared to the control mice. ${ }^{66}$ Mice with heme-supplemented diet also showed higher number of large adenomatous polyps than the those with control diet. ${ }^{66}$

\section{Secondary bile acids}

Diet rapidly alters the gut microbiome. ${ }^{67}$ As bile acids are involved in the absorption of dietary fat in the intestine, ${ }^{68}$ high-fat diets (HFDs) induce an increase in bile secretion. Liver secretes cholic and chenodeoxycholic acids. Secondary bile acids are the metabolites produced by intestinal bacteria from primary bile acids. Large bowel anaerobic bacteria deconjugates and dehydroxylates, cleaving glycine and taurine residues to form the secondary bile acids such as deoxycholic acid and lithocholic acid. ${ }^{29,60}$ Metagenomic analysis showed that the microbial bile salt hydrolase activity is identified in all major bacterial divisions in the gut. ${ }^{69}$ Bile salt hydrolase confer bile tolerance and hence improvement in survival of bacteria in murine intestine. ${ }^{69}$ However, to the host, continuous exposure to the certain hydrophobic bile acids may induce oxidative DNA damage that might lead to tumorigenesis. ${ }^{68}$ In serum and bile of patients with colonic adenomas, more deoxycholic acid was detected than in healthy controls. ${ }^{70}$ Secondary bile acids are toxic to several cell systems at physiological concentrations. ${ }^{70}$ Direct installation of secondary bile acids in the large bowel can be tumor promoting. Infusion of deoxycholic acid led to damage of the mucosa, provoking increased cell proliferation. ${ }^{71}$ Deoxycholic acid has been reported to cause resistance to apoptosis, as suggested from tissue specimens ${ }^{72}$ and cell-line studies. ${ }^{73}$ Microbial genes encoding for secondary bile acid production were more abundant in African Americans with high risk of colon cancer, whereas those encoding for methanogenesis and hydrogen sulfide production were higher in rural native Africans with low risk of the disease. ${ }^{30}$ Fecal secondary bile acid concentrations were higher in African Americans, whereas SFCAs were higher in native Africans. ${ }^{30}$

\section{FUNGI}

Yeast constitutes $<0.1 \%$ of microbiota. Most yeast isolates from the gastrointestinal tract are Candida albicans, and Torulopsis glabratra and $C$. tropicalis are occasionally discovered. ${ }^{74}$ Saccharomyces boulardii, one strain of yeast, has been used as a probiotic for the treatment and prevention of diarrhea. ${ }^{74}$ In recent study investigating human colonic mucosa, they reported an increase in biodiversity of fungal microbiota in sporadic cancer patients. ${ }^{14}$ They also found a trend of increased proportion of Basidiomycota in colitis-associated cancer mucosa, implying a local dysbiosis. ${ }^{14}$

\section{AGE, GENDER AND MICROBIOTA}

Microbiota undergoes changes according to age. ${ }^{75}$ A pyrosequencing study of fecal microbiota showed that the core microbiota of elderly subjects is different from that of younger adults, having a greater proportion of Bacteroides species and distinct abundance patterns of Clostridium groups. ${ }^{75}$ In centenarians, the microbiota is characterized by a rearrangement 
in the Firmicutes population and enrichment in facultative anaerobes such as pathobionts. ${ }^{76}$ The age-related change directs the elderly intestines to be in a high proinflammatory status through chronic age-related stimulation of macrophage. ${ }^{76,77} \mathrm{~A}$ recent study reported the regional difference of gut bacteria in old age rats. ${ }^{78}$ The old rats showed the higher abundance of Ruminococcaceae and Lachnospiraceae, which breakdown polysaccharides to produce butyrate. ${ }^{78}$ Notably, Deltaproteobacteria, a sulfate-reducing bacteria to produce genotoxic $\mathrm{H}_{2} \mathrm{~S}$, was significantly increased with aging in rat cecum. ${ }^{78}$ Recently we published the article regarding microbial changes and host response in F344 rat colon depending on sex and age following an HFD which suggests a link between HFD-induced gut dysbiosis (particularly the low species richness and high abundance ratios of Desulfovibrio spp. and C. lavalense) and cell proliferation of colon mucosa (indicated by Ki67 $\mathrm{IHC}$ ). ${ }^{79}$ In addition, sex difference influenced the response of gut microbiome to HFD particularly in old age, and it might be linked to the differences of inflammation in the colon mucosa according to gender. ${ }^{79}$

\section{CONCLUSION}

The role of microbiota is a hot topic not only in the gastroenterological area including inflammatory bowel disease, irritable bowel disease and colon cancer but also in the depression and autism. Recently there has been a big progress in the studies on metabolic properties of microbiota such as butyrate production, facilitation of heme toxicity, bile acid transformation, and nitrate reduction which contribute to colon carcinogenesis. In this review article we tried to summarize the comprehensive information regarding microbiota and colon cancer including recent scientific evidence. Further research on this subject could suggest noble preventive measures for the disease.

\section{ACKNOWLEDGMENTS}

This work was supported by a grant from the National Research Foundation of Korea (NRF) funded by the government of the Republic of Korea (2016R1A2B4013133).

And we thank prof. Hyuk Yoon for giving us valuable comments to improve this review article.

\section{CONFLICTS OF INTEREST}

No potential conflicts of interest were disclosed.

\section{REFERENCES}

1. Ferlay J, Soerjomataram I, Dikshit R, Eser S, Mathers C, Rebelo M, et al. Cancer incidence and mortality worldwide: sources, methods and major patterns in GLOBOCAN 2012. Int J Cancer 2015; 136:E359-86.

2. Aran V, Victorino AP, Thuler LC, Ferreira CG. Colorectal cancer: epidemiology, disease mechanisms and interventions to reduce onset and mortality. Clin Colorectal Cancer 2016;15:195-203.

3. Thursby $\mathrm{E}$, Juge $\mathrm{N}$. Introduction to the human gut microbiota. Biochem J 2017;474:1823-36.

4. Hooper LV, Littman DR, Macpherson AJ. Interactions between the microbiota and the immune system. Science 2012;336: 1268-73.

5. Gill SR, Pop M, DeBoy RT, Eckburg PB, Turnbaugh PJ, Samuel BS, et al. Metagenomic analysis of the human distal gut microbiome. Science 2006:312:1355-9.

6. Sender R, Fuchs S, Milo R. Revised estimates for the number of human and bacteria cells in the body. PLoS Biol 2016;14: e1002533.

7. Egert M, De Graaf AA, Smidt H, de Vos WM, Venema K. Beyond diversity: functional microbiomics of the human colon. Trends Microbiol 2006;14:86-91.

8. Possemiers S, Bolca S, Verstraete W, Heyerick A. The intestinal microbiome: a separate organ inside the body with the metabolic potential to influence the bioactivity of botanicals. Fitoterapia 2011;82:53-66.

9. Dulal S, Keku TO. Gut microbiome and colorectal adenomas. Cancer J 2014:20:225-31.

10. Fearon ER, Vogelstein B. A genetic model for colorectal tumorigenesis. Cell 1990;61:759-67.

11. Levy M, Thaiss CA, Elinav E. The microbiota: a new player in the etiology of colorectal cancer. Curr Colorectal Cancer Rep 2014; 10:1-8.

12. Rowland IR. The role of the gastrointestinal microbiota in colorectal cancer. Curr Pharm Des 2009;15:1524-7.

13. Marchesi JR, Dutilh BE, Hall N, Peters WH, Roelofs R, Boleij A, et al. Towards the human colorectal cancer microbiome. PLoS One 2011;6:e20447.

14. Richard ML, Liguori G, Lamas B, Brandi G, da Costa G, Hoffmann TW, et al. Mucosa-associated microbiota dysbiosis in colitis associated cancer. Gut Microbes 2018:4:131-42.

15. Sun J, Kato I. Gut microbiota, inflammation and colorectal cancer. Genes Dis 2016;3:130-43.

16. Johansson ME, Phillipson M, Petersson J, Velcich A, Holm L, Hansson GC. The inner of the two Muc2 mucin-dependent mucus layers in colon is devoid of bacteria. Proc Natl Acad Sci U S A 2008; 105:15064-9.

17. Kelsall B. Recent progress in understanding the phenotype and function of intestinal dendritic cells and macrophages. Mucosal Immunol 2008;1:460-9.

18. Tlaskalová-Hogenová H, Stepánková R, Hudcovic T, Tucková L, Cukrowska B, Lodinová-Zádníková $\mathrm{R}$, et al. Commensal bacteria (normal microflora), mucosal immunity and chronic inflammatory and autoimmune diseases. Immunol Lett 2004:93:97-108.

19. Vannucci L, Stepankova R, Kozakova H, Fiserova A, Rossmann P, Tlaskalova-Hogenova H. Colorectal carcinogenesis in germ-free 
and conventionally reared rats: different intestinal environments affect the systemic immunity. Int J Oncol 2008;32:609-17.

20. Akira S, Hemmi H. Recognition of pathogen-associated molecular patterns by TLR family. Immunol Lett 2003;85:85-95.

21. Bland PW. Mucosal T cell-epithelial cell interactions, mucosal $\mathrm{T}$ cells. New York, Karger Publishers, 1998:40-63.

22. Donaldson GP, Ladinsky MS, Yu KB, Sanders JG, Yoo BB, Chou WC, et al. Gut microbiota utilize immunoglobulin A for mucosal colonization. Science 2018;360:795-800.

23. Cebra JJ. Influences of microbiota on intestinal immune system development. Am J Clin Nutr 1999;69:1046s-51s

24. Reddy BS, Narisawa T, Maronpot R, Weisburger JH, Wynder EL. Animal models for the study of dietary factors and cancer of the large bowel. Cancer Res 1975;35:3421-6.

25. Funabashi H, Uchida K, Kado S, Matsuoka Y, Ohwaki M. Establishment of a Tcrb and Trp53 genes deficient mouse strain as an animal model for spontaneous colorectal cancer. Exp Anim 2001:50:41-7.

26. Kado S, Uchida K, Funabashi H, Iwata S, Nagata Y, Ando M, et al. Intestinal microflora are necessary for development of spontaneous adenocarcinoma of the large intestine in T-cell receptor beta chain and p53 double-knockout mice. Cancer Res 2001;61:2395-8.

27. Dove WF, Clipson L, Gould KA, Luongo C, Marshall DJ, Moser AR, et al. Intestinal neoplasia in the ApcMin mouse: independence from the microbial and natural killer (beige locus) status. Cancer Res 1997:57:812-4.

28. Tomkovich S, Yang Y, Winglee K, Gauthier J, Mühlbauer M, Sun $\mathrm{X}$, et al. Locoregional effects of microbiota in a preclinical model of colon carcinogenesis. Cancer Res 2017;77:2620-32.

29. Louis P, Hold GL, Flint HJ. The gut microbiota, bacterial metabolites and colorectal cancer. Nat Rev Microbiol 2014;12:661-72.

30. Ou J, Carbonero F, Zoetendal EG, DeLany JP, Wang M, Newton K, et al. Diet, microbiota, and microbial metabolites in colon cancer risk in rural Africans and African Americans. Am J Clin Nutr 2013;98:111-20

31. Brownawell AM, Caers W, Gibson GR, Kendall CW, Lewis KD, Ringel Y, et al. Prebiotics and the health benefits of fiber: current regulatory status, future research, and goals. J Nutr 2012; 142:962-74

32. Rivière A, Selak M, Lantin D, Leroy F, De Vuyst L. Bifidobacteria and butyrate-producing colon bacteria: importance and strategies for their stimulation in the human gut. Front Microbiol 2016; 7:979.

33. Encarnação J, Abrantes AM, Pires AS, Botelho MF. Revisit dietary fiber on colorectal cancer: butyrate and its role on prevention and treatment. Cancer Metastasis Rev 2015;34:465-78.

34. Chen J, Vitetta L. Inflammation-modulating effect of butyrate in the prevention of colon cancer by dietary fiber. Clin Colorectal Cancer 2018;17:e541-4.

35. Donohoe DR, Collins LB, Wali A, Bigler R, Sun W, Bultman SJ. The Warburg effect dictates the mechanism of butyrate-mediated histone acetylation and cell proliferation. Mol Cell 2012;48: 612-26.

36. Wu X, Wu Y, He L, Wu L, Wang X, Liu Z. Effects of the intestinal microbial metabolite butyrate on the development of colorectal cancer. J Cancer 2018;9:2510-7.

37. Humphreys KJ, Conlon MA, Young GP, Topping DL, Hu Y, Winter $\mathrm{JM}$, et al. Dietary manipulation of oncogenic microRNA ex- pression in human rectal mucosa: a randomized trial. Cancer Prev Res (Phila) 2014;7:786-95.

38. Furusawa Y, Obata Y, Fukuda S, Endo TA, Nakato G, Takahashi D, et al. Commensal microbe-derived butyrate induces the differentiation of colonic regulatory T cells. Nature 2013;504:446-50.

39. Conlon MA, Bird AR, Clarke JM, Le Leu RK, Christophersen CT, Lockett TJ, et al. Lowering of large bowel butyrate levels in healthy populations is unlikely to be beneficial. J Nutri 2015;145:1030-1.

40. Singh N, Gurav A, Sivaprakasam S, Brady E, Padia R, Shi H, et al. Activation of Gpr109a, receptor for niacin and the commensal metabolite butyrate, suppresses colonic inflammation and carcinogenesis. Immunity 2014:40:128-39.

41. Van den Abbeele P, Belzer C, Goossens M, Kleerebezem M, De Vos WM, Thas $\mathrm{O}$, et al. Butyrate-producing Clostridium cluster XIVa species specifically colonize mucins in an in vitro gut model. ISME J 2013;7:949-61.

42. Velasquez-Manoff M. Gut microbiome: the peacekeepers. Nature 2015:518:S3-11

43. Wu N, Yang X, Zhang R, Li J, Xiao X, Hu Y, et al. Dysbiosis signature of fecal microbiota in colorectal cancer patients. Microb Ecol 2013;66:462-70.

44. Whitehead RH, Young GP, Bhathal PS. Effects of short chain fatty acids on a new human colon carcinoma cell line (LIM1215). Gut 1986;27:1457-63.

45. Freeman HJ. Effects of differing concentrations of sodium butyrate on 1,2-dimethylhydrazine-induced rat intestinal neoplasia. Gastroenterology 1986;91:596-602.

46. Deschner EE, Ruperto JF, Lupton JR, Newmark HL. Dietary butyrate (tributyrin) does not enhance AOM-induced colon tumorigenesis. Cancer Lett 1990:52:79-82.

47. Archer SY, Meng S, Shei A, Hodin RA. p21(WAF1) is required for butyrate-mediated growth inhibition of human colon cancer cells. Proc Natl Acad Sci U S A 1998;95:6791-6.

48. O'Keefe SJ, Ou J, Aufreiter S, O'Connor D, Sharma S, Sepulveda J, et al. Products of the colonic microbiota mediate the effects of diet on colon cancer risk. J Nutr 2009;139:2044-8.

49. Donohoe DR, Garge N, Zhang X, Sun W, O'Connell TM, Bunger MK, et al. The microbiome and butyrate regulate energy metabolism and autophagy in the mammalian colon. Cell Metab 2011;13:517-26.

50. Belcheva A, Irrazabal T, Robertson SJ, Streutker C, Maughan H, Rubino S, et al. Gut microbial metabolism drives transformation of Msh2-deficient colon epithelial cells. Cell 2014;158:288-99.

51. Teixeira TF, Grześkowiak Ł, Franceschini SC, Bressan J, Ferreira CL, Peluzio MC. Higher level of faecal SCFA in women correlates with metabolic syndrome risk factors. Br J Nutr 2013;109:914-9.

52. Payne AN, Chassard C, Zimmermann M, Müller P, Stinca S, Lacroix $\mathrm{C}$. The metabolic activity of gut microbiota in obese children is increased compared with normal-weight children and exhibits more exhaustive substrate utilization. Nutr Diabetes 2011;1:e12

53. Lupton JR. Microbial degradation products influence colon cancer risk: the butyrate controversy. J Nutr 2004;134:479-82.

54. Zeng H, Lazarova DL, Bordonaro M. Mechanisms linking dietary fiber, gut microbiota and colon cancer prevention. World J Gastrointest Oncol 2014;6:41-51.

55. Ferrario C, Taverniti V, Milani C, Fiore W, Laureati M, De Noni I, et al. Modulation of fecal Clostridiales bacteria and butyrate by 
probiotic intervention with Lactobacillus paracasei DG varies among healthy adults. J Nutr 2014;144:1787-96.

56. Kim DH, Jin YH. Intestinal bacterial beta-glucuronidase activity of patients with colon cancer. Arc Pharm Res 2001;24:564-7.

57. Liong MT. Roles of probiotics and prebiotics in colon cancer prevention: postulated mechanisms and in-vivo evidence. Int J Mol Sci 2008;9:854-63.

58. Kulkarni N, Reddy BS. Inhibitory effect of Bifidobacterium longum cultures on the azoxymethane-induced aberrant crypt foci formation and fecal bacterial beta-glucuronidase. Proc Soc Exp Biol Med 1994:207:278-83.

59. Rowland I, Granli T, Bøckman OC, Key PE, Massey RC. Endogenous $\mathrm{N}$-nitrosation in man assessed by measurement of apparent total $\mathrm{N}$-nitroso compounds in faeces. Carcinogenesis 1991;12:1395-401.

60. Rowland RHIR. Metabolic activities of the gut microflora in relation to cancer. Microb Ecol Health Dis 2000;12:179-85.

61. Kobayashi J. Effect of diet and gut environment on the gastrointestinal formation of N-nitroso compounds: a review. Nitric Oxide 2018;73:66-73.

62. Massey RC, Key PE, Mallett AK, Rowland IR. An investigation of the endogenous formation of apparent total $\mathrm{N}$-nitroso compounds in conventional microflora and germ-free rats. Food Chem Toxicol 1988;26:595-600.

63. Ijssennagger N, Derrien M, van Doorn GM, Rijnierse A, van den Bogert B, Müller M, et al. Dietary heme alters microbiota and mucosa of mouse colon without functional changes in host-microbe cross-talk.. PLoS One 2012;7:e49868.

64. Gamage SMK, Dissabandara L, Lam AK, Gopalan V. The role of heme iron molecules derived from red and processed meat in the pathogenesis of colorectal carcinoma. Crit Rev Oncol Hematol 2018;126:121-8.

65. Ijssennagger N, Belzer C, Hooiveld GJ, Dekker J, van Mil SW, Müller M, et al. Gut microbiota facilitates dietary heme-induced epithelial hyperproliferation by opening the mucus barrier in colon. Proc Natl Acad Sci U S A 2015;112:10038-43.

66. Constante M, Fragoso G, Calvé A, Samba-Mondonga M, Santos MM. Dietary heme induces gut dysbiosis, aggravates colitis, and potentiates the development of adenomas in mice. Front Microbiol 2017;8:1809.
67. David LA, Maurice CF, Carmody RN, Gootenberg DB, Button JE, Wolfe BE, et al. Diet rapidly and reproducibly alters the human gut microbiome. Nature 2013:505:559-63.

68. Barrasa JI, Olmo N, Lizarbe MA, Turnay J. Bile acids in the colon, from healthy to cytotoxic molecules. Toxicol In Vitro 2013;27:964-77.

69. Jones BV, Begley M, Hill C, Gahan CG, Marchesi JR. Functional and comparative metagenomic analysis of bile salt hydrolase activity in the human gut microbiome. Proc Natl Acad Sci U S A 2008; 105:13580-5.

70. Nagengast FM, Grubben MJ, van Munster IP. Role of bile acids in colorectal carcinogenesis. Eur J Cancer 1995:31:1067-70.

71. Rafter JJ, Eng VW, Furrer R, Medline A, Bruce WR. Effects of calcium and $\mathrm{pH}$ on the mucosal damage produced by deoxycholic acid in the rat colon. Gut 1986;27:1320-9.

72. Payne CM, Bernstein H, Bernstein C, Garewal H. Role of apoptosis in biology and pathology: resistance to apoptosis in colon carcinogenesis. Ultrastruct Pathol 1995;19:221-48.

73. Powell AA, Akare S, Qi W, Herzer P, Jean-Louis S, Feldman RA, et al. Resistance to ursodeoxycholic acid-induced growth arrest can also result in resistance to deoxycholic acid-induced apoptosis and increased tumorgenicity. BMC Cancer 2006;6:219.

74. Czerucka D, Piche T, Rampal P. Review article: yeast as probiotics -saccharomyces boulardii. Aliment Pharmacol Ther 2007;26:767-78.

75. Claesson MJ, Cusack S, O'Sullivan O, Greene-Diniz R, de Weerd H, Flannery E, et al. Composition, variability, and temporal stability of the intestinal microbiota of the elderly. Proc Natl Acad Sci U S A 2011;108 Suppl 1:4586-91.

76. Biagi E, Nylund L, Candela M, Ostan R, Bucci L, Pini E, et al. Through ageing, and beyond: gut microbiota and inflammatory status in seniors and centenarians. PloS One 2010;5:e10667.

77. Franceschi C, Bonafè M, Valensin S, Olivieri F, De Luca M, Ottaviani E, et al. Inflamm-aging: an evolutionary perspective on immunosenescence. Ann N Y Acad Sci 2000;908:244-54.

78. Lee SM, Kim N, Park JH, Nam RH, Yoon K, Lee DH. Comparative analysis of ileal and cecal microbiota in aged rats. J Cancer Prev 2018;23:70-6.

79. Lee SM, Kim N, Yoon H, Nam RH, Lee DH. Microbial changes and host response in F344 rat colon depending on sex and age following a high-fat diet. Front Microbiol 2018;9:2236. 